\title{
Nimotuzumab, an EGFR-targeted antibody, promotes radiosensitivity of recurrent esophageal squamous cell carcinoma
}

\author{
YANG YU ${ }^{1,2}$, HUI GUAN ${ }^{3}$, LIYANG JIANG ${ }^{2}$, XIAOLIN $\mathrm{LI}^{2}$, LIGANG XING ${ }^{2}$ and XIAORONG SUN ${ }^{4}$ \\ ${ }^{1}$ School of Medicine and Life Sciences, Shandong Academy of Medical Sciences, University of Jinan, Jinan, \\ Shandong 250031; ${ }^{2}$ Department of Radiation Oncology, Shandong Cancer Hospital and Institute, \\ Shandong First Medical University and Shandong Academy of Medical Sciences, Jinan, Shandong 250117; \\ ${ }^{3}$ Department of Radiation Oncology, The Fourth People's Hospital of Jinan, Jinan, Shandong 250031; \\ ${ }^{4}$ Department of Nuclear Medicine, Shandong Cancer Hospital Affiliated to Shandong University, \\ Shandong Cancer Hospital and Institute, Shandong First Medical University and \\ Shandong Academy of Medical Sciences, Jinan, Shandong 250117, P.R. China
}

Received June 24, 2019; Accepted December 12, 2019

DOI: 10.3892/ijo.2020.4981

\begin{abstract}
Local tumor recurrence is one of the main causes for the failure of esophageal cancer treatment following radiotherapy. Previous studies have demonstrated that epidermal growth factor receptor (EGFR)-targeted therapy combined with radiotherapy is expected to become an effective means to control tumor recurrence. The aim of the present study was to investigate the effect and mechanism of nimotuzumab (an EGFR-targeted antibody) in the treatment of recurrent esophageal carcinoma. The radiation responses of two esophageal squamous carcinoma cell lines, EC109 and TE-1, with or without nimotuzumab, were first evaluated by CCK-8 assay. Colony formation and apoptosis were used to measure anti-proliferation effects. It was demonstrated that nimotuzumab arrested the cell cycle at the $\mathrm{G} 2$ phase in vitro. Western blotting and immunofluorescence analysis were used to determine signaling pathway changes. It was observed that nimotuzumab inhibited phosphorylation of EGFR in EC109 cells. Furthermore, recurrent tumor models were established and it was identified that the degree of tumor hypoxia was positively associated with EGFR overexpression. In EC109 cell xenografts, nimotuzumab combined with radiation led to a significant delay in recurrent tumor growth compared with that
\end{abstract}

Correspondence to: Dr Xiaorong Sun, Department of Nuclear Medicine, Shandong Cancer Hospital Affiliated to Shandong University, Shandong Cancer Hospital and Institute, Shandong First Medical University and Shandong Academy of Medical Sciences, 440 Jiyan Road, Jinan, Shandong 250117, P.R. China

E-mail: 251400067@qq.com

Key words: esophageal cancer, nimotuzumab, epidermal growth factor receptor, hypoxia, radiotherapy, recurrence of radiation alone $(\mathrm{P}<0.001$ for 0 Gy pre-irradiation, $\mathrm{P}=0.005$ for $20 \mathrm{~Gy}$ pre-irradiation, $\mathrm{P}=0.005$ for $10 \mathrm{~Gy}$ pre-irradiation). These results suggest that nimotuzumab combined with radiation may be an effective means to control recurrent esophageal squamous cell carcinoma with EGFR overexpression.

\section{Introduction}

Esophageal cancer has a high incidence in East Asia, with annual morbidity and mortality rates that rank third and fourth among all cancers, retrospectively, based on analysis of 2012 East Asian cancer statistics (1). The major histological type in East Asia is squamous cell carcinoma. Despite ongoing research regarding treatments for esophageal squamous cell carcinoma (ESCC), the long-term survival rates remain poor (2). As the majority of patients are diagnosed with locally advanced disease and are not suitable for curative surgery, definitive chemo-radiotherapy or radiotherapy have became the main treatment modalities (3). However, the local tumor recurrence rate is as high as 30-40\% following radiotherapy (4), which is one of the main causes of treatment failure. Therefore, re-irradiation combined with systemic chemotherapy is often the only choice; however, re-irradiation is difficult to perform. In radical radiotherapy, local normal tissue can receive high radiation doses, therefore a radical irradiation dose cannot be administered to the recurred tumor (5). Notably, the impact of irradiation on the tumor microenvironment, which predominately consists of damage to tumor microvascules, may increase the hypoxia fraction in recurred tumors, which leads to radiotherapy resistance $(6,7)$. Therefore, an efficacious therapy with minimal toxicity that improves the efficacy of radiotherapy is urgently needed.

A recurrent tumor xenograft model can be established to simulate the clinical situation of the tumor. This widely accepted approach involves administering a certain dose of radiation to the transplantation site prior to tumor cell transplantation. In a variety of animal experiments with different 
recurrence tumor models, it has been found that the level of hypoxia in recurrent tumors is significantly higher compared with in normal tumors $(8,9)$. In addition, epidermal growth factor receptor (EGFR) overexpression is observed in hypoxic regions $(10,11)$. Additionally, EGFR overexpression in esophageal cancer has been identified to be inversely associated with tumor radiocurability $(12,13)$. In a number or studies, EGFR overexpression has been demonstrated to be associated with lower tumor control rates following irradiation $(14,15)$. EGFR overexpression is also correlated with poor disease-free and overall survival rates in patients with esophageal adenocarcinoma (16). Previous studies have reported that nimotuzumab can improve the radiosensitivity of lung cancer and brain tumors with high expression of EGFR $(17,18)$. Therefore, EGFR-targeted therapy combined with radiotherapy is expected to become an effective method to control recurrent tumors. Nimotuzumab, an important EGFR-targeted antibody, is currently used clinically in combination with radiotherapy and is approved for treating esophageal cancer $(19,20)$. However, to the best of our knowledge, there has been no preclinical study of the radiosensitivity of nimotuzumab in recurrent esophageal cancer. Therefore, the present study investigated the efficacy of the anti-EGFR therapy on recurrent ESCC radiotherapy and the potential underlying mechanisms in vitro and in vivo.

\section{Materials and methods}

Drug and chemicals. Nimotuzumab was provided by Baitai Bio Pharmaceutical Co., Ltd. Nimotuzumab was dissolved in saline ( $0.9 \%$ sodium chloride) to the required concentration and stored in the dark at $4^{\circ} \mathrm{C}$ for follow-up experiments.

Cell culture and antibodies. The human esophageal cancer cell lines EC-109 (Chinese Academy of Sciences) and TE-1 (Shanghai Institute of Cell Bank) were cultured in RPMI-1640 medium (Gibco; Thermo Fisher Scientific, Inc.), supplemented with $10 \%$ fetal bovine serum (Gibco; Thermo Fisher Scientific, Inc.), penicillin $(100 \mathrm{U} / \mathrm{ml})$ and streptomycin $(100 \mu \mathrm{g} / \mathrm{ml})$. The cells were cultured under normoxic $\left(20 \% \mathrm{O}_{2}\right)$ or hypoxic conditions $\left(0.2 \% \mathrm{O}_{2}\right)$. The temperature of culture was $37^{\circ} \mathrm{C}$. PBS with $1 \%$ BSA was used as the primary antibody diluent. Hypoxia-inducible factor 1- $\alpha$ (HIF-1 $\alpha$; cat. no. ABE279; EMD Millipore; western blotting, 1:1,000; immunohistochemistry, 1:100) and carbonic anhydrase 9 (CA9; cat. no. D120346; Sangon Biotech, Co. Ltd; western blotting, 1:1,000; immunohistochemistry, 1:100) antibodies were used for western blotting and staining. The cleaved caspase-3 rabbit $\mathrm{mAb}$ (cat. no. 9664; western blotting, 1:1,000), EGFR rabbit mAb (cat. no. 2085; western blotting, 1:1,000; immunohistochemistry, 1:100; immunofluorescence, 1:250), anti-phosphorylated (p)-EGFR rabbit mAb (cat. no. 3777; western blotting, 1:1,000; immunohistochemistry, 1:800; immunofluorescence, 1:400), Bcl-2 rabbit mAb (cat. no. 2870; western blotting, 1:1,000) and caspase-3 rabbit mAb (cat. no. 9665; western blotting, 1:1,000) were purchased from Cell Signaling Technology, Inc. CDK1 rabbit mAb (cat. no. ab133327; western blotting, 1:10,000), Cdc25c rabbit mAb (cat. no. ab32444; western blotting, 1:2,000), Bax rabbit mAb (cat. no. ab32503; western blotting, 1:2,000), cyclin $\mathrm{B} 1$ rabbit $\mathrm{mAb}$ (cat. no. ab32053; western blotting, 1:5,000), cyclin A2 rabbit mAb (cat. no. ab181591; western blotting, 1:2,000) and cyclin D1 rabbit $\mathrm{mAb}$ (cat. no. ab134175; western blotting, 1:10,000) were purchased from Abcam.

Western blot analysis. The esophageal cancer cells were lysed on ice for 5 min with RIPA lysis buffer (Beyotime Institute of Biotechnology) and then centrifuged for $10 \mathrm{~min}$ at $4^{\circ} \mathrm{C}$ and $10,800 \mathrm{x} g$ to separate the supernatant as the protein extract. The protein concentration was measured using the BCA assay kit (Beyotime Institute of Biotechnology). Total protein $(20 \mu \mathrm{g})$ from each sample was dissolved on a 12\% Bis-Tris gel with MOPS running buffer and transferred to nitrocellulose membranes. The membrane was blocked with 5\% milk-TBST (10 nm Tris-HCl, pH 7.5; $150 \mathrm{mM}, 0.05 \%$ Tween-20) and incubated overnight at room temperature with antibodies against HIF-1 $\alpha$, CA9, cleaved caspase-3, caspase-3, EGFR, p-EGFR, Bcl-2, CDK1, Cdc25c, Bax, cyclin B1, cyclin A2 and cyclin D1. The membrane was then washed with TBST and incubated for $1 \mathrm{~h}$ with a goat anti-rabbit secondary antibody (1:3,000; Cell Signaling Technology, Inc.). The protein bands were detected using G:BOX (Syngene) with Chemiluminescent horseradish peroxidase substrate (EMD Millipore). The data were analyzed using ImageJ software (version 1.8.0; National Institutes of Health) and GraphPad Prism software (version 7.04; GraphPad Software, Inc.).

CCK-8 assay. For proliferative curve measurement, EC109 and TE-1 cells were divided into the following groups: i) Control (untreated); ii) Nitmotuzumab treatment group $(25 \mu \mathrm{g} / \mathrm{ml}$, $24 \mathrm{~h}$ ); iii) radiotherapy group (5 Gy); and iv) drug combined radiotherapy group (5 Gy $12 \mathrm{~h}$ post-nimotuzumab treatment), and treated at $37^{\circ} \mathrm{C}$. Esophageal cancer cells $(2,000 / 100 \mu \mathrm{l} /$ well $)$ were seeded in 96-well plates with the supplemented RPMI-1640 medium (control) or the supplemented RPMI-1640 medium containing nitmotuzumab $(25 \mu \mathrm{g} / \mathrm{ml})$ for the treatment and combined groups. The cells were then incubated for $2 \mathrm{~h}$ with CCK-8 reagent (10 $\mu$; Dojindo Molecular Technologies). The optical density value was measured using a microplate reader at a wavelength of $450 \mathrm{~nm}$.

Colony formation assay. Cells (2,000/100 $\mu \mathrm{l} /$ well) were seeded in 6-well dishes and divided into the four aforementioned groups. The cells were cultured in drug-free supplemented RPMI-1640 medium for 10-14 days, and then fixed in $4 \%$ paraformaldehyde for $15 \mathrm{~min}$ at room temperature and stained with crystal violet for $20 \mathrm{~min}$ at room temperature. The stained cells were then counted after photographs were obtained using a light microscope (magnification, x100).

Cell cycle and apoptosis assays. EC109 and TE-1 esophageal cancer cells were divided into the four aforementioned groups. Subsequently, the cells were fixed with $70 \%$ ethanol $(2 \mathrm{ml})$ for $48-72 \mathrm{~h}$ at $4^{\circ} \mathrm{C}$. Apoptosis was assessed by Annexin V and propidium iodide (PI) staining using the Apoptosis Detection kit (cat. no. 88-8102-74; Invitrogen; Thermo Fisher Scientific, Inc.). At room temperature, aliquots of $1 \times 10^{5}$ cells were incubated with Annexin V/PI for $15 \mathrm{~min}$. Cells were then analyzed by flow cytometry with a two-color fluorescence-activated cell sorting flow cytometer. 
Animal xenograft models. A total of 150 female nude mice (18-22 g; 4-6 weeks old) were purchased from Huafukang Biotechnology Co., Ltd. Animal experimental protocols were approved by the Institutional Animal Experimentation Committee of Shandong Cancer Hospital (Shandong, China). To generate tumor xenografts, the right hind legs of the mice were subcutaneously injected with $4 \times 10^{6}$ EC109 cells or $1 \times 10^{7}$ TE- 1 cells. The tumors were measured with a digital caliper in three orthogonal dimensions ( $\mathrm{a}, \mathrm{b}$ and $\mathrm{c}$ ), and the volume of tumor was calculated as $\pi \mathrm{abc} / 6$ (21). When the volume of tumors reached $\sim 150 \mathrm{~mm}^{3}$, the tumor growth delay assay was performed. Three different tumor models were established: i) common xenograft model, Pre-IR 0 Gy; ii) recurrent tumor model 1 , tumors were allowed to continue grow after 20 Gy irradiation, Pre-IR 20 Gy; and iii) recurrent tumor model 2: the right hind leg was irradiated with 10 Gy X-ray 24 h before tumor implantation, Pre-IR 10 Gy, according to previously published studies $(22,23)$. Then mice were randomly divided into the following groups: i) Untreated control; ii) irradiation alone; iii) nimotuzumab alone; iv) and irradiation+nimotuzumab ( $n=6$ per group). The different mouse models are presented in Fig. S1.

Tumor irradiation and growth delay assays. The tumor irradiation equipment, a X-ray irradiator (X-rad225Cx; National Instruments Corporation), was provided by the laboratory of Shandong Cancer Hospital (Shandong, China). The mice under anesthesia (Ketamine, $80 \mathrm{mg} / \mathrm{kg}$ BW; Xylazine $10 \mathrm{mg} / \mathrm{kg}$ $\mathrm{BW}, \mathrm{IP}$ ) were given a total of $30 \mathrm{~Gy}$ in six fractions (5 Gy every other day) over the course of 3 weeks. Tumor-bearing mice in the experimental group were injected intravenously with nimotuzumab at a single dose of $1.0 \mathrm{mg}$ (24). Tumor-bearing mice in the control and radiation alone groups (used as controls) were injected with $0.9 \%$ sodium chloride. Radiation therapy began $6 \mathrm{~h}$ after drug treatment. As described in our previous study (21), the relative tumor volume (RTV) was calculated as follows: $\mathrm{RTV}=\mathrm{Vt} / \mathrm{V}_{0}$, where $\mathrm{Vt}$ is the volume of tumor at any given time and $\mathrm{V}_{0}$ is the initial volume before treatment. The RTV values were recorded and the tumor growth delay curve was analyzed.

Immunohistochemistry and immunofluorescence staining. Immunohistochemistry was performed as described previously (21). The mice were sacrificed by pentobarbital $(100 \mathrm{mg} / \mathrm{kg})$ followed by cervical dislocation, then half of the tumors were removed quickly, embedded in optimal cutting medium (OCT 4583; Sakura Finetek) and frozen until use in immunofluorescence experiments. The other half of the tumors were fixed overnight (within $12 \mathrm{~h}$ ) at $25^{\circ} \mathrm{C}$ in $10 \%$ formalin and embedded in paraffin blocks, from which 4- $\mu \mathrm{m}$ thick sections were prepared for immunohistochemical staining. For immunohistochemistry, the paraffin-embedded tumors were sectioned and dewaxed. After antigen retrieval was performed using $10 \mathrm{mmol} / \mathrm{l}$ citrate buffer, sections were incubated with $3 \% \mathrm{H}_{2} \mathrm{O}_{2}$ and blocked with $5 \% \mathrm{BSA}$ at $37^{\circ} \mathrm{C}$ for $30 \mathrm{~min}$. The sections were then incubated with HIF-1 $\alpha$, CA9, EGFR and p-EGFR primary antibodies at $4^{\circ} \mathrm{C}$ overnight. After rewarming at room temperature the next day, the sections were incubated with secondary antibody (1:200; cat. no. A-21442; Thermo Fisher Scientific, Inc.) using the two-step polymer
HRP (cat. no. PV-9005; OriGene Technologies, Inc.) detection system at room temperature for $1 \mathrm{~h}$. The samples were visualized using 3,3-diaminobenzidine.

For immunofluorescence, $8-10 \mu \mathrm{m}$ sections were fixed with $4 \%$ paraformaldehyde for at $4^{\circ} \mathrm{C}$ for $20 \mathrm{~min}$ and blocked with $5 \% \mathrm{BSA}$ at $37^{\circ} \mathrm{C}$ for $30 \mathrm{~min}$. Then the sections were incubated with EGFR and p-EGFR primary antibodies at $4^{\circ} \mathrm{C}$ overnight. After being rewarmed for $1 \mathrm{~h}$, samples were washed and incubated with specific secondary antibody (1:200; cat. no. A-21442; Thermo Fisher Scientific, Inc.) using the two-step polymer HRP (cat. no. PV-9005; OriGene Technologies, Inc.) for $1 \mathrm{~h}$ at $37^{\circ} \mathrm{C}$. After washing three times, nuclei were stained with DAPI for $5 \mathrm{~min}$ at room temperature. Fluorescence images were captured used a Nikon H600L ECLIPSE 90i fluorescence microscope (Nikon Corporation; magnification, $\mathrm{x} 400$ ) and immunohistochemistry images were acquired using a light microscope (Olympus Corporation; magnification, $x 400)$. EGFR and p-EGFR were imaged using red filters.

Statistical analysis. SPSS (version 16.0; SPSS, Inc.) was used for data analyses. Quantitative data are expressed as the mean \pm standard error. All experiments were performed a minimum of three times. One-way ANOVA followed by Bonferroni's post hoc test was used to compare multiple groups. $\mathrm{P}<0.05$ was considered to indicate a statistically significant difference.

\section{Results}

Nimotuzumab enhances the radiation response of ESCC cells with high expression of EGFR in vitro. To investigate the effect of nimotuzumab and radiotherapy on ESCC proliferation in vitro, EC109 and TE-1 cells were treated with nimotuzumab alone or in combination with radiotherapy, and then analyzed by CCK-8 assay. The results (Fig. 1A) demonstrated that the viability of EC109 cells with radiotherapy and nimotuzumab was markedly decreased compared with the radiotherapy alone group $(\mathrm{P}<0.001)$, whereas the viability of TE-1 cells [the cell line with low levels of EGFR (20)] treated with radiotherapy and nimotuzumab was not significantly different compared with the radiotherapy alone group $(\mathrm{P}=0.215)$. Additionally, a colony formation assay was used to assess whether radiotherapy and nimotuzumab affected the ability of the two cell lines to form colonies. As presented in Fig. 1B, compared with the radiotherapy alone group, EC109 cells with radiotherapy and nimotuzumab exhibited a significant decrease in the number of colonies $(\mathrm{P}<0.01)$, and colonies were smaller. Whereas, in TE-1 cells, compared with the radiotherapy alone group, combined radiotherapy and nimotuzumab did not decrease the number of colonies $(\mathrm{P}=0.85)$. These data demonstrated that nimotuzumab could enhance the sensitivity of ESCC cells with high expression of EGFR to radiotherapy in vitro.

Nimotuzumab accelerates ESCC cell apoptosis. The present study further examined whether nimotuzumab alone or combined with radiotherapy could influence the apoptosis of ESCC cells. In EC109 cells, it was observed that the apoptosis rate was significantly increased in the combination treatment group compared with the radiotherapy alone group 

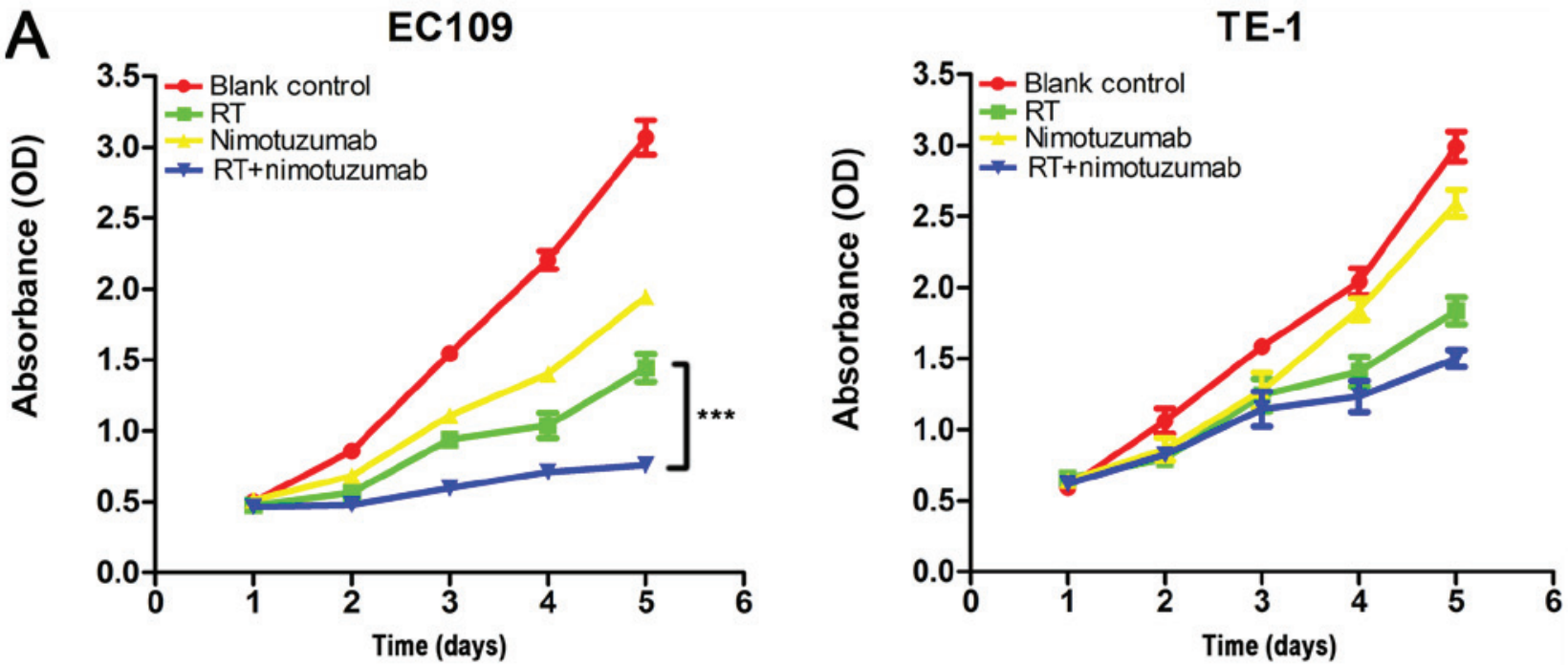

B
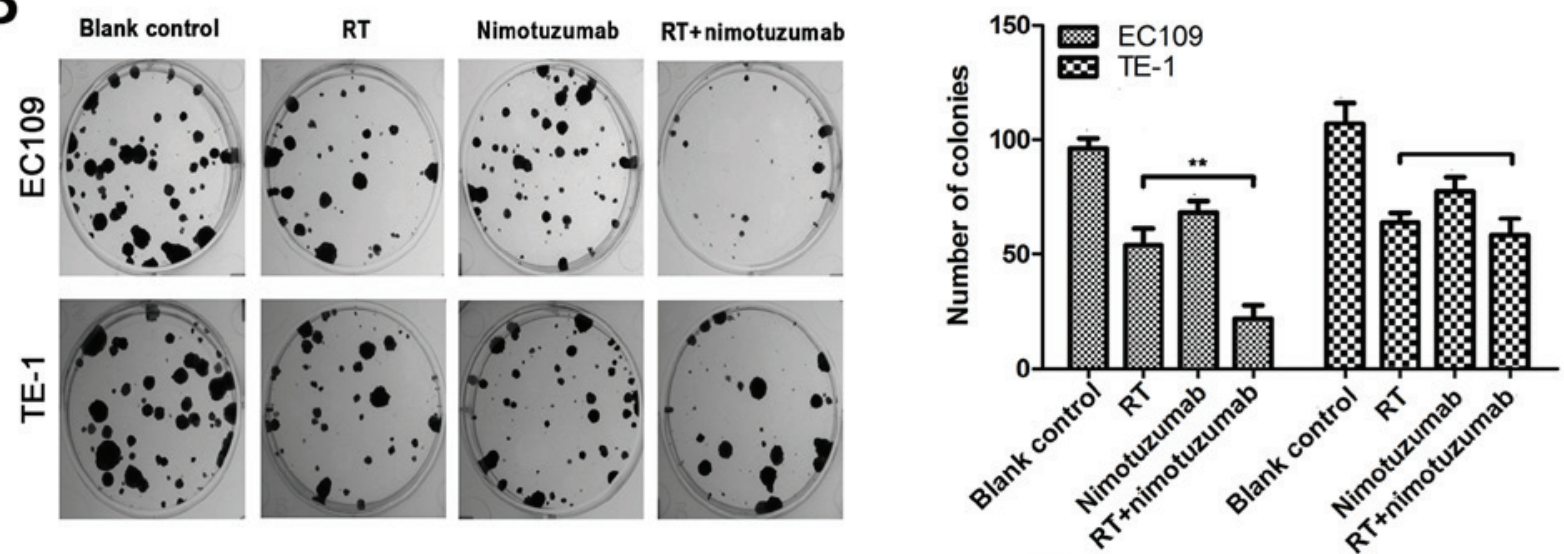

Figure 1. Nimotuzumab enhances the radiation response of esophageal squamous cell carcinoma cells with high expression of epidermal growth factor receptor. (A) The proliferation of EC109 cells treated with nimotuzumab and RT was decreased, as demonstrated by CCK-8 assay. (B) Colony formation assay revealed a decreased ability of colony-formation following treatment with RT and nimotuzumab, particularly in EC109 cells. ${ }^{* *} \mathrm{P}<0.01$ and ${ }^{* * *} \mathrm{P}<0.001$. RT, radiotherapy.

$(\mathrm{P}<0.01)$. However, no similar result was observed in TE-1 cells ( $\mathrm{P}>0.05$; Fig. 2A and B). Additionally, to investigate the mechanism of nimotuzumab alone or combination with radiotherapy-induced apoptosis, the present study examined apoptosis-related caspase-3, anti-apoptotic protein Bcl-2 and pro-apoptotic protein Bax in ESCC cells. As presented in Fig. $2 \mathrm{C}$, the protein expression of caspase-3 was decreased in the RT+nimotuzumab group compared with the RT group in EC109 cells, and cleaved caspase-3 was increased. In addition, $\mathrm{Bcl}-2$ was markedly decreased and Bax was increased in the $\mathrm{RT}+$ nimotuzumab group compared with the RT group, particularly in EC109 cells. Analysis of the relative expression of apoptosis proteins is presented in Fig. S2; for RT vs. combined groups, significant differences have been shown in TE-1 cells and EC109 cells). These data indicated that nitmotuzumab combined with radiotherapy could accelerate apoptosis in EC109 cells.

Nimotuzumab arrests the ESCC cell cycle at the G2 phase. As presented in Fig. 3A and B, the percentage of EC109 cells in the G2 phase was $79.56 \pm 2.86 \%$ for the radiotherapy+drug group, $56.22 \pm 0.37 \%$ for the radiotherapy group, $9.25 \pm 1.26 \%$ for the blank control and $25.14 \pm 1.19 \%$ for the drug group (combined vs. RT group, $\mathrm{P}<0.001)$. In addition, the percentage of TE-1 cells in the $\mathrm{G} 2$ phase was $37.01 \pm 0.66 \%$ for radiotherapy+drug group, $35.57 \pm 2.24 \%$ for the radiotherapy group, $18.71 \pm 4.04 \%$ for the blank control and $15.03 \pm 4.49 \%$ for the drug group (combined vs. RT group, $\mathrm{P}>0.05$ ). Furthermore, the percentages of ESCC cells in the G1 and S phases correspondingly decreased. In addition, the expression levels of several cell cycle kinases were examined in ESCC cells, including cyclin A2, cyclin D1, cyclin B1, CDK1 and Cdc25c. As shown in Fig. 3C, in EC109 cells, cyclin A2, cyclin B1, CDK1 and Cdc25c were decreased in the radiotherapy+drug group compared with the blank control, drug alone and radiotherapy alone groups. In TE-1 cells, cyclin B1, CDK1 and Cdc25c were decreased. However, no notable change was observed for cyclin $\mathrm{D} 1$, which is a regulator that drives cells from the G1 phase to $\mathrm{S}$ phase (25). All these data suggest that nimotuzumab induces cell cycle arrest at the $\mathrm{G} 2$ phase to inhibit cell proliferation.

Level of hypoxia increases in the recurrent esophageal tumor models. Western blot experiments revealed that HIF-1 $\alpha$ and CA9 levels were increased in hypoxic cells compared with 
A
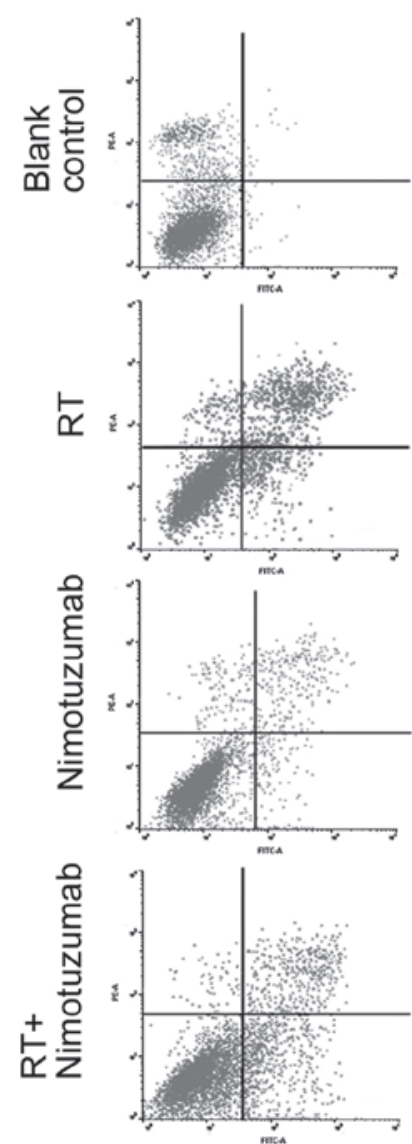

TE-1
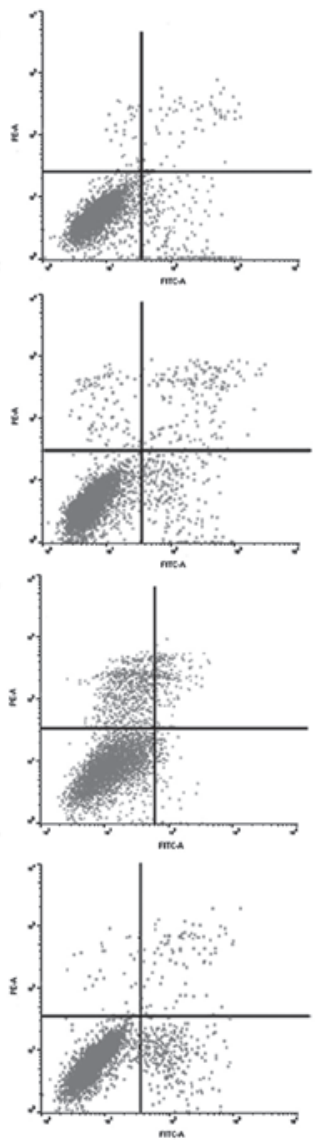

B
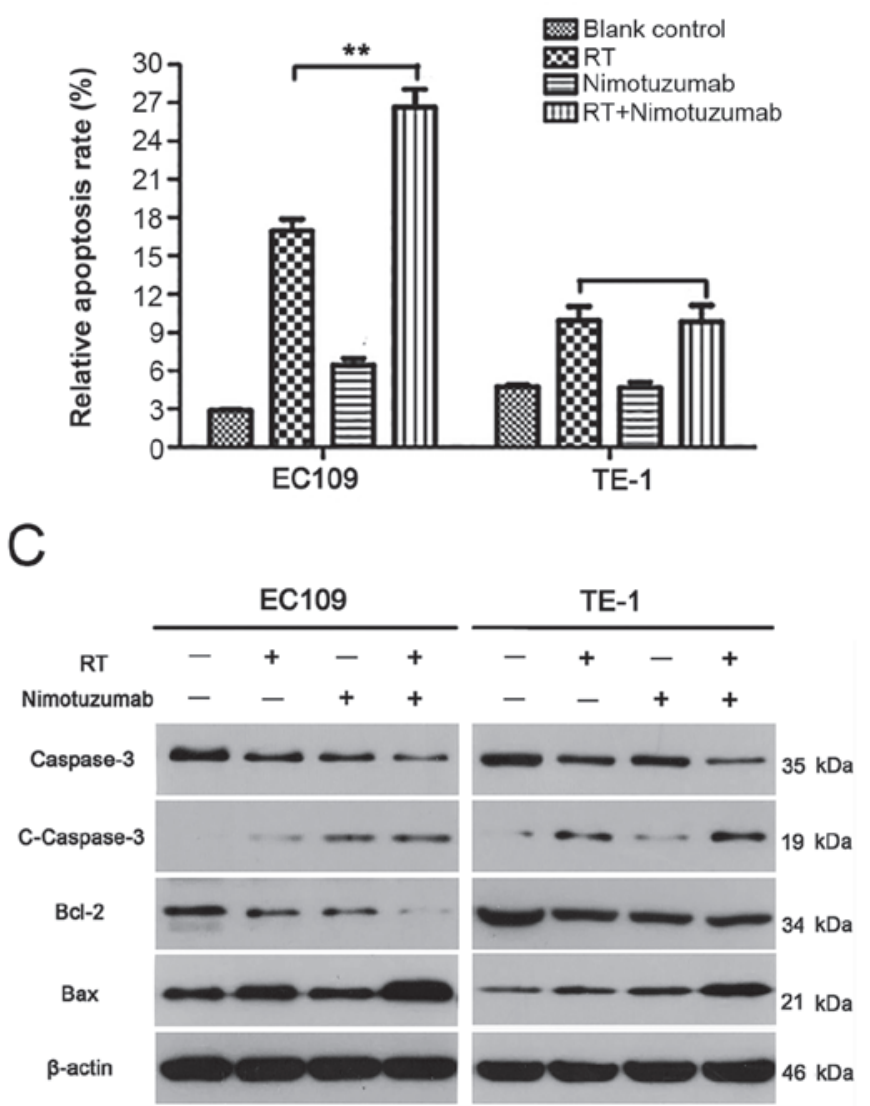

Figure 2. Nimotuzumab combined with RT accelerates esophageal squamous cell carcinoma cell apoptosis. (A and B) Nimotuzumab combined with RT accelerated EC109 cell apoptosis compared with the RT alone group. (C) The apoptotic markers c-caspase-3, caspase-3, Bcl-2 and Bax were detected by western blotting following treatment with nimotuzumab and $\mathrm{RT}$. ${ }^{* *} \mathrm{P}<0.01$ and ${ }^{* * *} \mathrm{P}<0.001$. RT, radiotherapy; c-, cleaved.

normoxic EC109 and TE1 cells (Fig. 4A and B). The relative expression levels of HIF-1 $\alpha$ and CA9 are presented in Figs. S3 and S4. It was demonstrated that nimotuzumab may downregulate the expression of Hif-1 $\alpha$ in EC109 cells during hypoxia, but no effect was observed for CA9, which needs to be further verified. As presented in Fig. 4C and D, the HIF-1 $\alpha$ and CA9 expression levels were also examined using immunohistochemical staining in the different xenograft models. In the nuclei and cytoplasm of 0 Gy pre-irradiated tumors, the content of HIF-1 $\alpha$ and CA9 protein was low; however, in the 10 Gy and 20 Gy pre-irradiated xenograft models, abundant levels of HIF-1 $\alpha$ (especially in the nucleus) and CA9 (especially in the cytoplasm) protein were observed in EC109 and TE1 tumors (Fig. 4C and D). These results suggested that the recurrent tumor models had been successfully constructed, and the degree of hypoxia had increased in recurrent tumors.

Tumor hypoxia is positively associated with EGFR overexpression. As shown in Fig. 5A, EGFR expression was markedly increased in hypoxic cells compared with normoxic cells, particularly in EC109 cells. The relative expression levels of p-EGFR and EGFR are presented in Figs. S5 and S6, and the ratio of p-EGFR/EGFR is shown in Fig. S7. As presented in Fig. S7, hypoxia increased the p-EGFR/EGFR ratio in EC109 cells. However, this result needs to be further verified.
In addition, the immunofluorescence studies demonstrated that EGFR and p-EGFR expression levels were markedly increased in the cell membrane in EC109 10 Gy and 20 Gy pre-irradiated models compared with the 0 Gy pre-irradiated tumor model. However, this effect was not detected in TE-1 cells (Fig. 5B and C). These results indicate that the level of tumor hypoxia was positively associated with EGFR overexpression in ESCC.

Nimotuzumab inhibits EGFR phosphorylation and increases radiosensitivity of recurrent ESCC cells with EGFR overexpression in vivo. The present study further investigated the mechanisms of nimotuzumab in the promotion of ESCC cell radiosensitivity. As presented in Figs. 5A, S5 and S6, nimotuzumab significantly downregulated the level of p-EGFR and EGFR in EC109 cells and hypoxic EC109 cells, indicating that the anti-EGFR effect of nimotuzumab is predominantly via a downregulated level of p-EGFR. However, this result was not obvious in TE-1 cells due to a low expression of EGFR. To confirm whether nimotuzumab could increase the radiosensitivity of ESCC cells in vivo, routine and recurrent ESCC xenograft models were established. As shown in Fig. 6A, expression levels of p-EGFR in tumors slides of ESCC cell xenografts following radiotherapy with nimotuzumab treatment were examined using immunofluorescence analysis. 
A
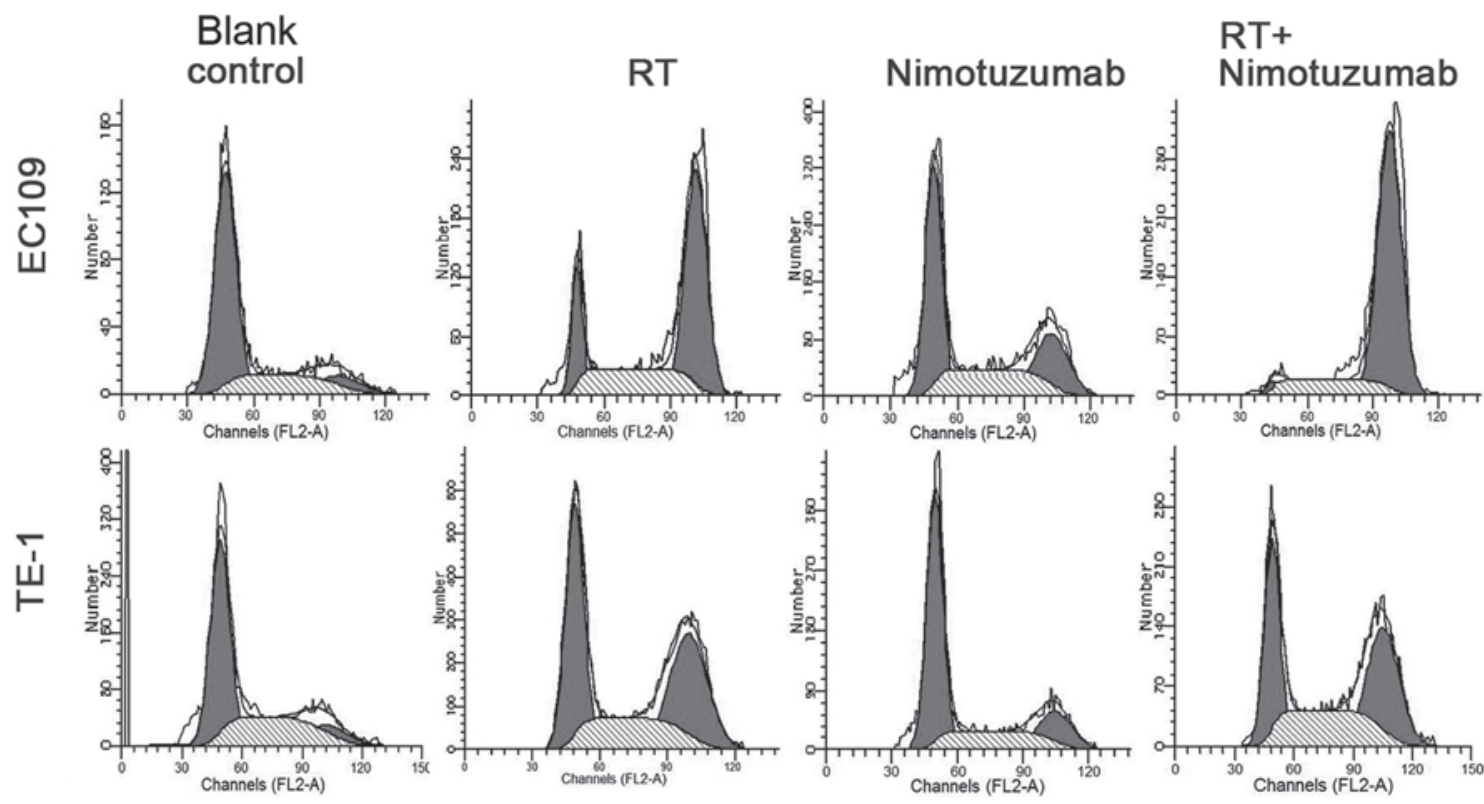

B

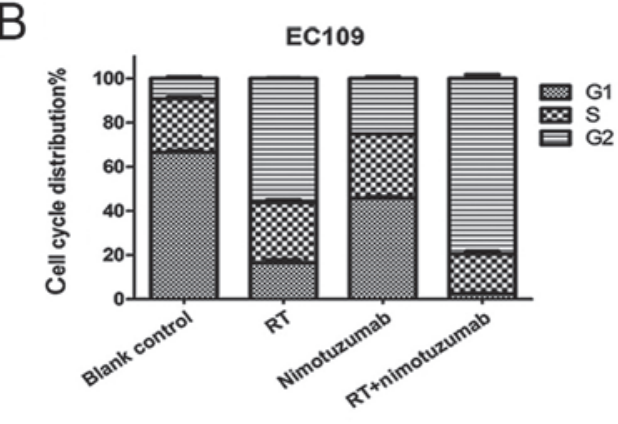

C
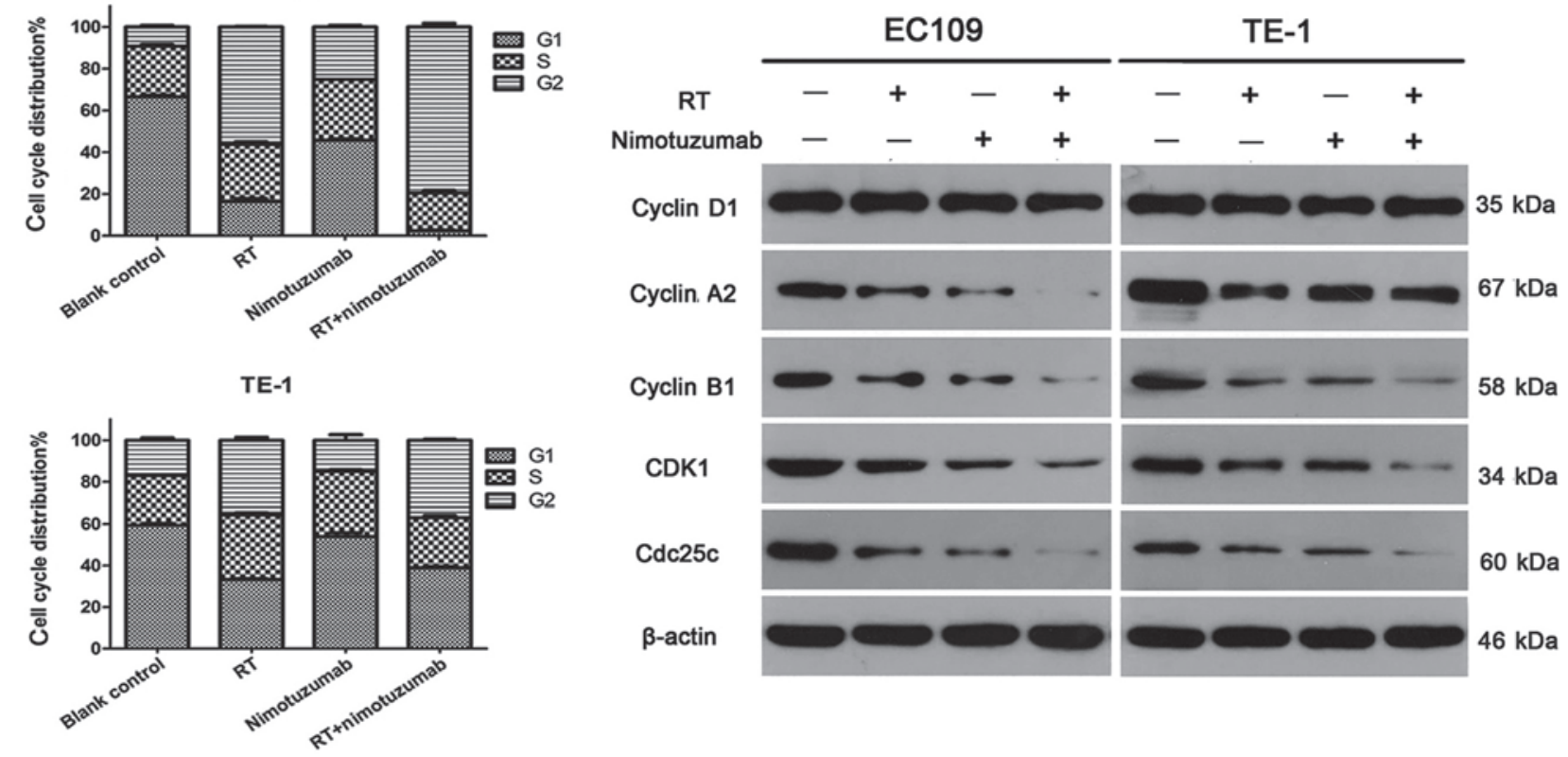

Figure 3. Nimotuzumab combined with RT arrests the ESCC cell cycle at the G2 phase. (A and B) Nimotuzumab combined with RT arrests the ESCC cell cycle at the G2 phase, particularly in EC109 cells. Combined vs. RT group, $\mathrm{P}<0.001$ for EC109 cells and $\mathrm{P}<0.05$ for TE-1 cells. (C) The cell cycle markers cyclin A2, cyclin D1, cyclin B1, CDK1 and Cdc25c were detected by western blotting following treatment with nimotuzumab and RT.. ESCC, esophageal squamous cell carcinoma; RT, radiotherapy.

Similar to the in vitro results, following treatment with nimotuzumab and radiotherapy, the level of p-EGFR was inhibited in the three xenograft EC109 tumor models (0 Gy, 10 Gy and 20 Gy pre-irradiated); however, this effect was not detected in TE-1 cells.

The tumor growth delay assay demonstrated that in EC109 xenografts, tumor growth was significantly inhibited in the groups treated with a combination of nimotuzumab and radiotherapy compared with those treated with radiation alone $(\mathrm{P}<0.001$ for $0 \mathrm{~Gy}$ pre-irradiation, $\mathrm{P}=0.005$ for $20 \mathrm{~Gy}$ pre-irradiation, $\mathrm{P}=0.005$ for $10 \mathrm{~Gy}$ pre-irradiation; Fig. $6 \mathrm{~B}$ ). However, in the TE-1 xenografts models, it was observed that tumor growth was inhibited by radiation, but there were no significant differences between the irradiation groups and groups also treated with nimotuzumab $(\mathrm{P}=0.071$ for $0 \mathrm{~Gy}$ pre-irradiation, $\mathrm{P}=0.096$ for 20 Gy pre-irradiation, $\mathrm{P}=0.091$ for $10 \mathrm{~Gy}$ pre-irradiation). The present results indicated that nimotuzumab could downregulate the levels of p-EGFR and increase radiosensitivity in both primary and recurrent EGFR-overexpressing ESCC cells.

\section{Discussion}

Local recurrence is one of the main causes for the failure of esophageal cancer treatment following radiotherapy. Secondary radiotherapy remains the most important 

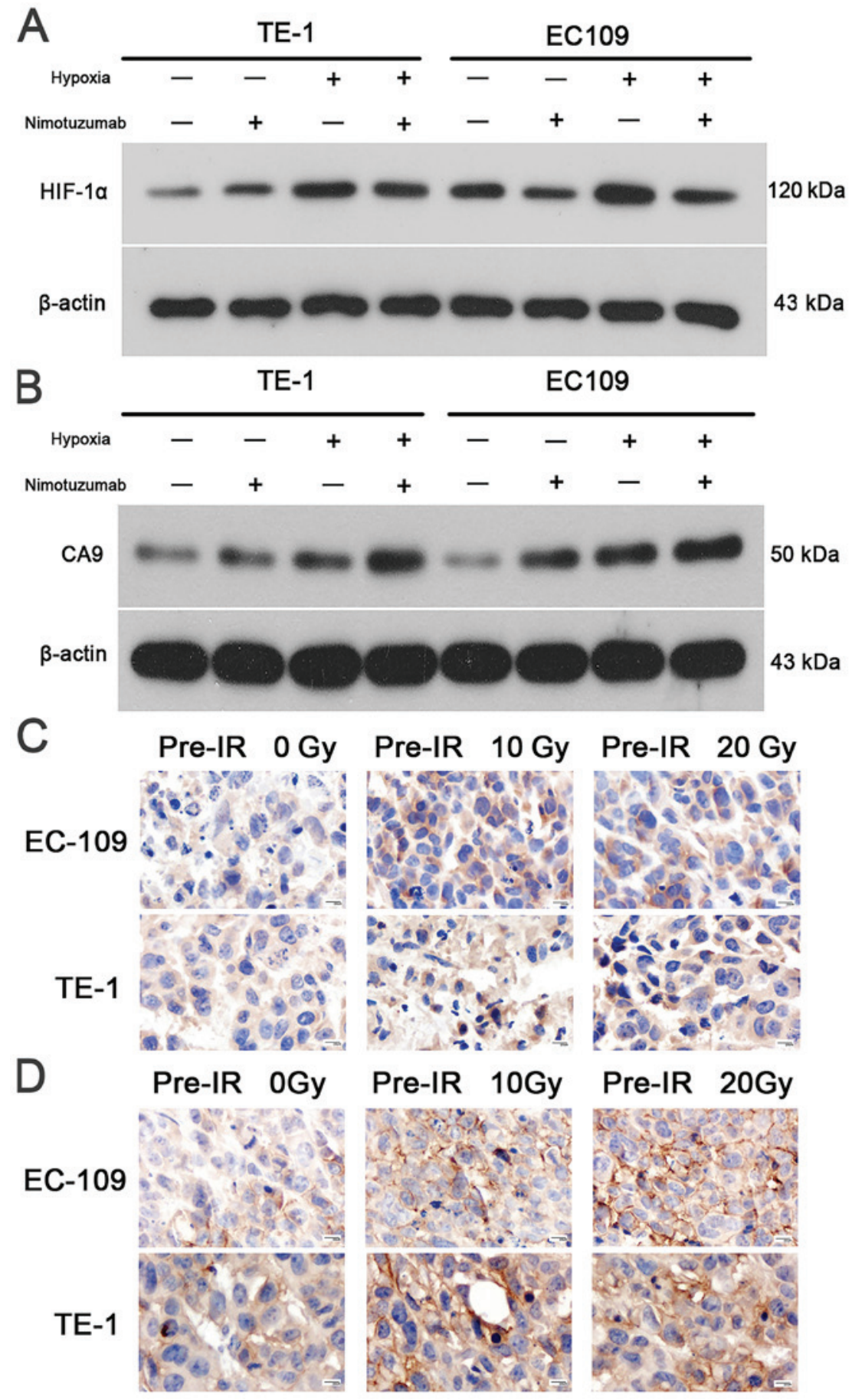

Figure 4. Level of hypoxia increases in the recurrent esophageal tumor models. (A and B) HIF-1 $\alpha$ and CA9 were detected by western blotting after treatment of normoxic and hypoxic esophageal squamous cell carcinoma cells with nimotuzumab. (C) The expression of HIF-1 $\alpha$ was detected by immunohistochemistry. (D) The expression level of CA9 was detected by immunohistochemistry. Magnification, x400. HIF-1 $\alpha$, hypoxia-inducible factor 1- $\alpha$; CA9, carbonic anhydrase 9; Pre-IR, pre-irradiation.

therapeutic method for recurrent tumors (3). As few preclinical research studies and clinical trials have reported a treatment for recurrent esophageal cancer, this was investigated in the present study. The current study measured the effect of nimotuzumab on radiation response of recurrent esophageal cancer and investigated the underling mechanisms in vitro and in vivo. The results demonstrated that nimotuzumab could enhance the radiation response of EC109 cells, which exhibit a high expression of EGFR, both in primary and recurrent cells. However, similar results were not found in TE-1 cells, which exhibit low EGFR expression. Previous studies have demonstrated that the antitumor effect of EGFR inhibitors is due to restrained ligand binding to EGFR, which inhibits EGFR activation $(26,27)$. To investigate the potential mechanisms of nimotuzumab in the improvement of radiosensitivity, the expression levels of EGFR and p-EGFR were detected in ESCC cells. The results revealed that expression of EGFR was increased in the hypoxic (recurrent) cells compared with in primary EC109 and TE-1 cells. Nimotuzumab treatment decreased the p-EGFR level in EC109, but not in TE-1 cells. 


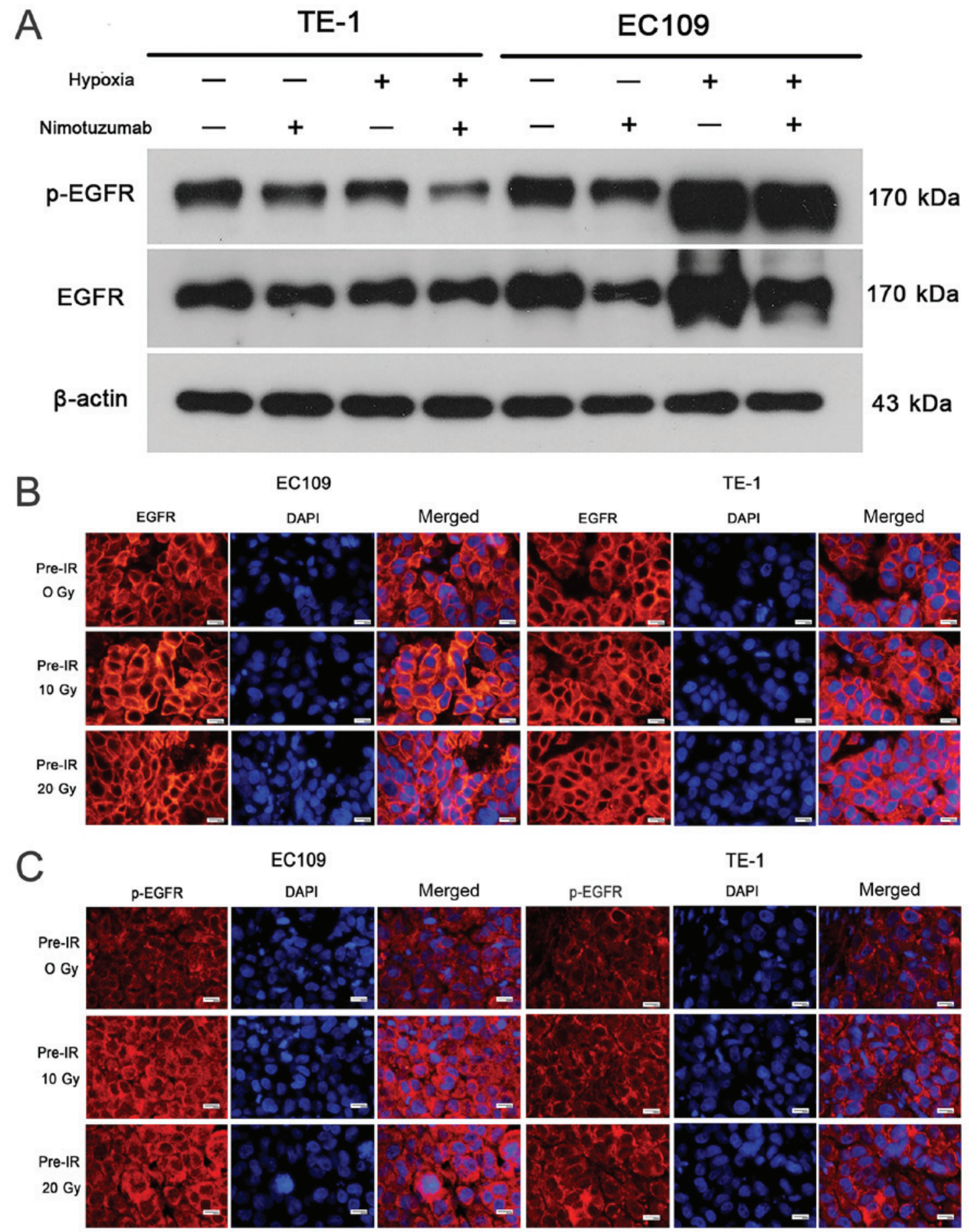

Figure 5. Tumor hypoxia is positively associated with EGFR overexpression. (A) EGFR and p-EGFR levels were detected by western blotting after treatment of normoxic and hypoxic esophageal squamous cell carcinoma cells with nimotuzumab. (B) The expression of EGFR was detected by immunofluorescence. (C) The expression of p-EGFR was detected by immunofluorescence. Magnification, x400. EGFR and p-EGFR were stained red, and DAPI was stained blue. EGFR, epidermal growth factor receptor; p-, phosphorylated.

These data demonstrated that nimotuzumab inhibited the activation of EGFR in EGFR-overexpressing ESCC cells, and hypoxia may be involved in the regulation of EGFR overexpression and its ligands. The findings of the present study are valuable for further clinical translational studies for the following reasons. Firstly, nimotuzumab enhanced the radiation response of EGFR-overexpressing ESCC cells. Secondly, in future clinical situations, it is necessary to assess EGFR expression in patients with recurrent esophageal tumors.
Retrospective trials have shown that EGFR inhibitor can improve the radiotherapy response and local control of certain cancer types, including rectal, lung and brain cancer, providing a new treatment strategy for anticancer therapy $(14,28)$. However, the SCOPE1 (29) and RTOG 0436 (30) trials demonstrated that adding cetuximab to definitive chemoradiotherapy in patients with localized esophageal cancer failed to improve the patients' survival. These phase III trials demonstrated little benefit to current 
A

EC109

p-EGFR

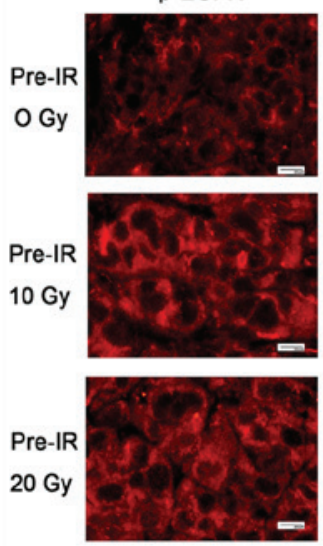

B
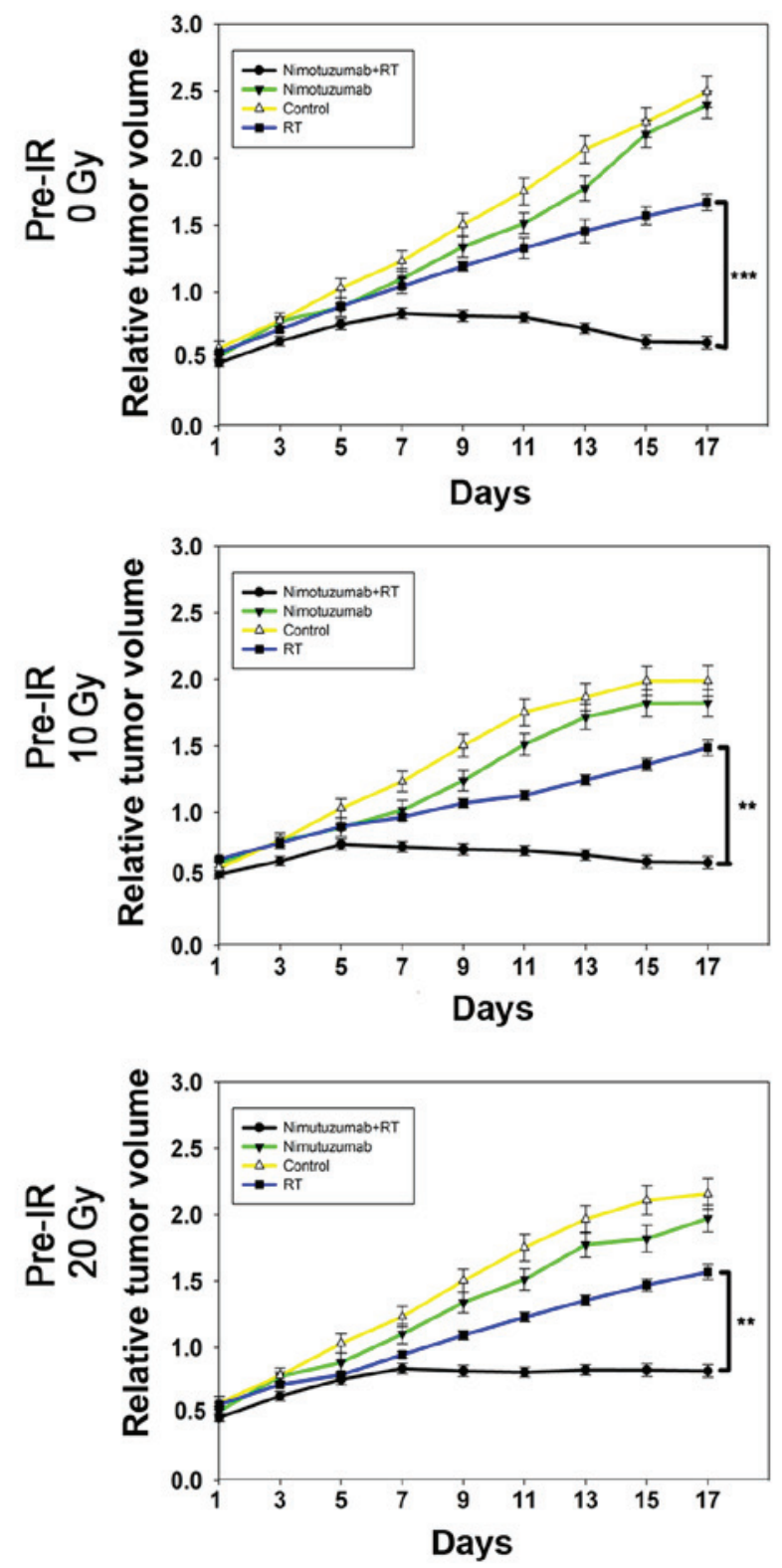

TE-1
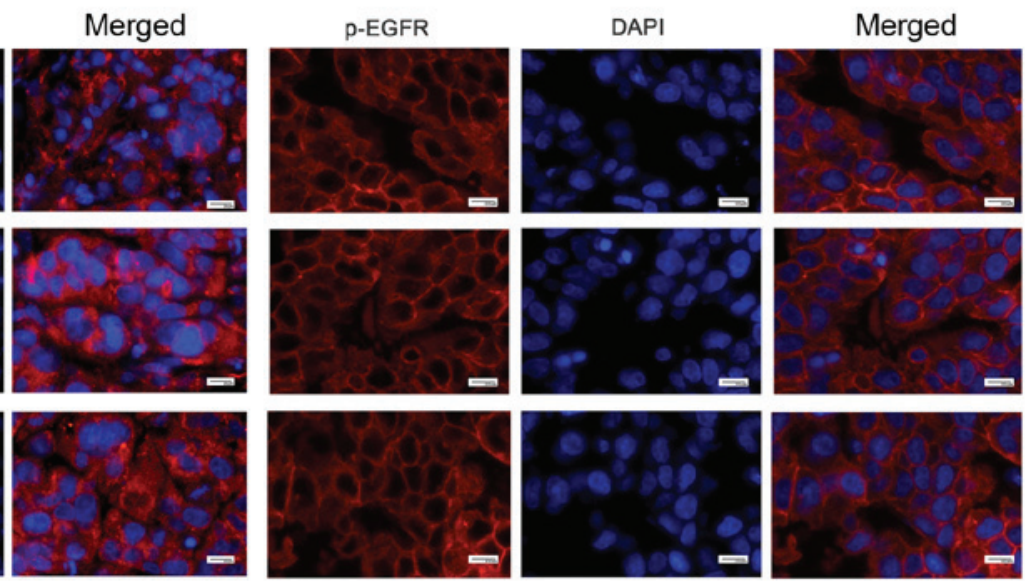

TE-1
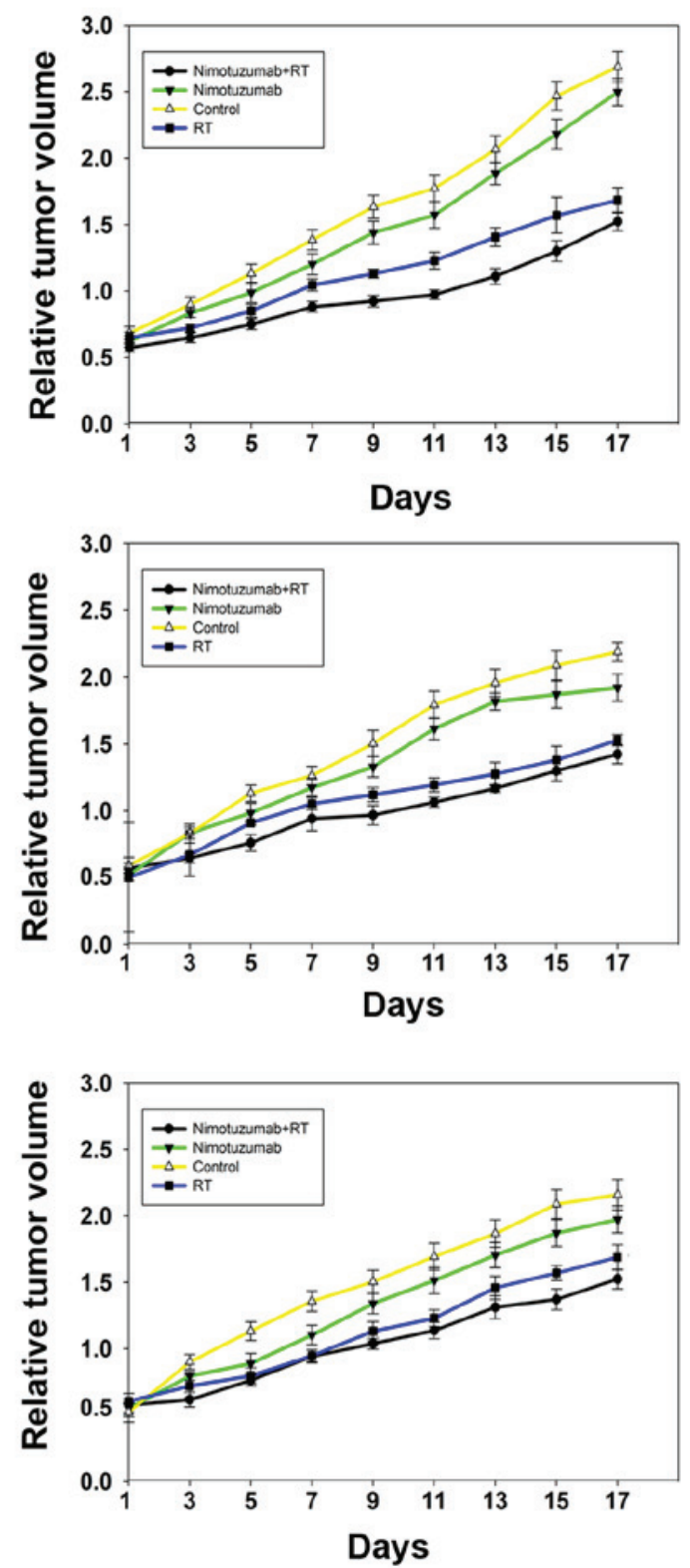

Figure 6. Effects of nimotuzumab on the response of ESCC xenograft models to RT. (A) The expression levels of p-EGFR were detected by immunofluorescence of three ESCC xenograft tumor models $(0 \mathrm{~Gy}, 10 \mathrm{~Gy}$ and $20 \mathrm{~Gy}$ pre-irradiated) following treatment with nimotuzumab and RT. p-EGFR was inhibited in the majority of RT-treated EC109 xenografts compared with the untreated xenografts, while most cells had low expression of p-EGFR in TE-1 xenograft tumors. (B) Tumor growth delay cure. ${ }^{* *} \mathrm{P}<0.01,{ }^{* * *} \mathrm{P}<0.001$. ESCC, esophageal squamous cell carcinoma; RT, radiotherapy; p-, phosphorylated; EGFR, epidermal growth factor receptor. 
EGFR-targeted agents in the patients with no detectable EGFR expression, and highlighted the need for predictive biomarkers in the treatment of esophageal cancer. Another EGFR inhibitor is nimotuzumab, a humanized IgG1 isotype monoclonal antibody of EGFR, which adheres to the cell surface to inhibit tumor growth by binding both antibody arms to two targets. Two phase II clinical trials $(31,32)$ and the NICE trial (33) evaluated the efficacy of nimotuzumab with definitive chemoradiotherapy in patients with advanced esophageal cancer, which revealed that a combination with nimotuzumab improved the patients local control rate, endoscopic complete response rate, pathological complete response rate and overall survival rate. Nimotuzumab is currently used in phase III clinical trials of concurrent chemoradiotherapy for esophageal cancer; which indicate that a combination with nimotuzumab is more effective (unpublished data).

Baumann et al (15) observed that the antitumor capabilities of nimotuzumab depend on EGFR expression levels. Zhao et al (24) demonstrated that nimotuzumab enhances the radiation response in KYSE30 cells with high EGFR expression; however, the effect is not observed in TE-1 cells with low EGFR expression. Akashi et al (18) observed that nimotuzumab enhances the radiosensitivity of NSCLC cell lines with high levels of EGFR expression. Compared with these previous studies, the present study also used two cell lines, in addition recurrent tumor models were constructed. Additionally, the present study focused on the effect of hypoxia on EGFR expression.

The present study demonstrated that the level of tumor hypoxia was positively associated with EGFR overexpression. The regulatory mechanism has been reported in previous studies (34-36), which is that hypoxia induces expression of EGFR and its ligands. In return, EGFR may enhance the response of cells to hypoxia by increasing the expression of HIF-1 $\alpha$, thereby acting as a survival factor for hypoxic cancer cells. EGFR signaling activates the PI3K/AKT pathway, which increases the level of HIF- $1 \alpha$. HIF-1 $\alpha$ then activates survivin gene transcription by direct binding to the survivin promoter (37). Several studies $(10,24)$ have shown that under normoxic or hypoxic conditions, the abundance of HIF-1 $\alpha$ protein increases with the activation of EGFR signaling, which is also achieved via the PI3K/AKT pathway. As described in our previous study (38), the present study succeeded in establishing a recurrent esophageal xenograft tumor model, which was characterized by a hypoxic microenvironment. The extent of hypoxia increase was assessed in the recurrent esophageal tumor models. Chen et al (23) reported similar results; the level of hypoxia increases in recurrent prostate tumor models, which is due to a lower microvascular density in pre-irradiated tissues. Compared with the study by Zhao et al (24), the present study verified that the anti-apoptotic protein $\mathrm{Bcl}-2$ and caspase- 3 were decreased, while pro-apoptotic Bax was increased when ESCC cells were treated with a combination of drug and radiation, demonstrating that treatment with nimotuzumab in combination with radiation promotes cell apoptosis, particularly in EC109 cells. Furthermore, in the present study, cyclin A2, cyclin B1, CDK1 and Cdc25c expression levels were markedly decreased following combined drug and radiotherapy treatment. By contrast, cyclin D1, an essential factor in the regulation of the cell cycle transition from G1 to $\mathrm{S}$ phase, was not affected; demonstrating that treatment with nimotuzumab affected the cell cycle at the G2 phase.

There are a number of limitations of the present study. It is understood that in the USA and other Western countries, the incidence of esophageal adenocarcinoma is equal to or exceeds the incidence of ESCC. Therefore, one limitation of the current study is that no esophageal adenocarcinoma cell lines were investigated. In addition, the lack of investigation of HIF-1 $\alpha$ translocation is another limitation.

In conclusion, the present study demonstrated that nimotuzumab enhanced the radiation response both in primary and recurrent ESCC cells with high expression of EGFR. Additionally, nimotuzumab accelerated ESCC cell apoptosis and arrested the ESCC cell cycle at the G2 phase. It was also identified that the degree of hypoxia was increased in recurrent tumors. Furthermore, the potential mechanisms of how nimotuzumab improves radiosensitivity were investigated, which revealed that nimotuzumab inhibits the activation of EGFR in ESCC cells with a high EGFR expression. In addition, it was found that the level of tumor hypoxia was positively associated with EGFR expression in ESCC and hypoxia may be involved in the regulation of EGFR and its ligands. However, further studies are required to clarify the precise mechanism and therapeutic significance of the hypoxic response and EGFR signaling pathway in cancer.

\section{Acknowledgements}

Not applicable.

\section{Funding}

The present study was supported by grants from the National Natural Science Foundation of China (grant no. 81572970), Shandong Provincial Natural Science Foundation (grant nos. ZR2015HZ004 and ZR2014YL033), the Subject Assignment of China National Key Research and Development Program (grant no. 2018YFC1313201), and the Jinan Scientific and Technology Development Project (grant no. 201805005).

\section{Availability of data and materials}

The datasets used and/or analyzed during the current study are available from the corresponding author on reasonable request.

\section{Authors' contributions}

XS designed the study and revised the draft. YY drafted the manuscript and completed the main experiments. HG created the figures and performed statistical analyses. XL performed the histological examination of the tumors. LX assisted in designing the study. LJ analyzed the data and revised the manuscript. All authors read and approved the final manuscript.

\section{Ethics approval and consent to participate}

The animal experiments were approved by the Animal Ethics Committee at the Shandong Cancer Hospital Affiliated to Shandong University (Jinan, China). 


\section{Patient consent for publication}

Not applicable.

\section{Competing interests}

The authors declare that they have no competing interests.

\section{References}

1. Torre LA, Bray F, Siegel RL, Ferlay J, Lortet-Tieulent J and Jemal A Global cancer statistics, 2012. CA Cancer J Clin 65: 87-108, 2015.

2. Malhotra GK, Yanala U, Ravipati A, Follet M, Vijayakumar M and Are C: Global trends in esophageal cancer. J Surg Oncol 115: 564-579, 2017.

3. Jha N, Harris J, Seikaly H, Jacobs JR, McEwan AJ and Robbins KT: A phase II study of submandibular gland transfer prior to radiation for prevention of radiation-induced xerostomia in head-and-neck cancer (RTOG 0244). Int J Radiat Oncol Biol Phys 84: 437-442, 2012.

4. Brown JM: Tumor hypoxia in cancer therapy. Methods Enzymol 435: 297-321, 2007.

5. Hengstler JG, Bockamp EO, Hermes M, Brulport M, Bauer A, Schormann W, Schiffer IB, Hausherr C, Eshkind L, Antunes C, et al: Oncogene-blocking therapies: New insights from conditional mouse tumor models. Curr Cancer Drug Targets 6: 603-612, 2006

6. Lee AWM, Ng WT, Chan JYW, Corry J, Mäkitie A, Mendenhall WM, Rinaldo A, Rodrigo JP, Saba NF Strojan P, et al: Management of locally recurrent nasopharyngeal carcinoma. Cancer Treat Rev 79: 101890, 2019.

7. Moeller BJ, Cao Y, Li CY and Dewhirst MW: Radiation activates HIF-1 to regulate vascular radiosensitivity in tumors: Role of reoxygenation, free radicals, and stress granules. Cancer Cell 5: 429-441, 2004

8. Harada H, Itasaka S, Zhu Y, Zeng L, Xie X, Morinibu A, Shinomiya $\mathrm{K}$ and Hiraoka M: Treatment regimen determines whether an HIF-1 inhibitor enhances or inhibits the effect of radiation therapy. Br J Cancer 100: 747-757, 2009.

9. Kwong LN, Zou L, Chagani S, Pedamallu CS, Liu M, Jiang S, Protopopov A, Zhang J, Getz G and Chin L: Modeling Genomic Instability and Selection Pressure in a Mouse Model of Melanoma. Cell Rep 19: 1304-1312, 2017.

10. Bussink J, van der Kogel AJ and Kaanders JH: Activation of the PI3-K/AKT pathway and implications for radioresistance mechanisms in head and neck cancer. Lancet Oncol 9: 288-296, 2008.

11. Nijkamp MM, Hoogsteen IJ, Span PN, Takes RP, Lok J, Rijken PF, van der Kogel AJ, Bussink J and Kaanders JH: Spatial relationship of phosphorylated epidermal growth factor receptor and activated AKT in head and neck squamous cell carcinoma. Radiother Oncol 101: 165-170, 2011.

12. Harari PM and Huang SM: Combining EGFR inhibitors with radiation or chemotherapy: Will preclinical studies predict clinical results? Int J Radiat Oncol Biol Phys 58: 976-983, 2004.

13. Milas L, Fan Z, Andratschke NH and Ang KK: Epidermal growth factor receptor and tumor response to radiation: In vivo preclinical studies. Int J Radiat Oncol Biol Phys 58: 966-971, 2004.

14. Giralt J, de las Heras M, Cerezo L, Eraso A, Hermosilla E, Velez D, Lujan J, Espin E, Rosello J, Majó J, et al; Grupo Español de Investigacion Clinica en Oncologia Radioterápica (GICOR): The expression of epidermal growth factor receptor results in a worse prognosis for patients with rectal cancer treated with preoperative radiotherapy: A multicenter, retrospective analysis. Radiother Oncol 74: 101-108, 2005.

15. Baumann M, Krause M, Dikomey E, Dittmann K, Dörr W, Kasten-Pisula U and Rodemann HP: EGFR-targeted anti-cancer drugs in radiotherapy: Preclinical evaluation of mechanisms. Radiother Oncol 83: 238-248, 2007.

16. Wang KL, Wu TT, Choi IS, Wang H, Resetkova E and Correa AM: Expression of epidermal growth factor receptor in esophageal and esophagogastric junction adenocarcinomas: association with poor outcome. Cancer 109: 658-667, 2007.

17. Diaz Miqueli A, Rolff J, Lemm M, Fichtner I, Perez R and Montero E: Radiosensitisation of U87MG brain tumours by anti-epidermal growth factor receptor monoclonal antibodies. $\mathrm{Br}$ J Cancer 100: 950-958, 2009.
18. Akashi Y, Okamoto I, Iwasa T, Yoshida T, Suzuki M, Hatashita E, Yamada Y, Satoh T, Fukuoka M, Ono K, et al: Enhancement of the antitumor activity of ionising radiation by nimotuzumab, a humanised monoclonal antibody to the epidermal growth factor receptor, in non-small cell lung cancer cell lines of differing epidermal growth factor receptor status. Br J Cancer 98: 749-755, 2008.

19. Kawaguchi Y, Kono K, Mimura K, Sugai H, Akaike H and Fujii H: Cetuximab induce antibody-dependent cellular cytotoxicity against EGFR-expressing esophageal squamous cell carcinoma. Int J Cancer 120: 781-787, 2007.

20. Zhao L, Li QQ, Zhang R, Xi M, Liao YJ, Qian D, He LR, Zeng YX, Xie D and Liu MZ: The overexpression of IGFBP-3 is involved in the chemosensitivity of esophageal squamous cell carcinoma cells to nimotuzumab combined with cisplatin. Tumour Biol 33: 1115-1123, 2012.

21. Yu Y, Li X, Xu H, Liu J, Dong M, Yang J, Sun L, Sun X and Xing L: Correlation of hypoxia status with radiosensitizing effects of sodium glycididazole: A preclinical study. Oncol Lett 15: 6481-6488, 2018.

22. Zips D, Eicheler W, Brüchner K, Jackisch T, Geyer P, Petersen C, van der Kogel AJ and Baumann M: Impact of the tumour bed effect on microenvironment, radiobiological hypoxia and the outcome of fractionated radiotherapy of human FaDu squamous-cell carcinoma growing in the nude mouse. Int $\mathrm{J}$ Radiat Biol 77: 1185-1193, 2001.

23. Chen FH, Chiang CS, Wang CC, Fu SY, Tsai CS, Jung SM, Wen CJ, Lee $\mathrm{CC}$ and Hong JH: Vasculatures in tumors growing from preirradiated tissues: Formed by vasculogenesis and resistant to radiation and antiangiogenic therapy. Int J Radiat Oncol Biol Phys 80: 1512-1521, 2011.

24. Zhao L, He LR, Xi M, Cai MY, Shen JX, Li QQ, Liao YJ, Qian D, Feng ZZ,Zeng YX, et al: Nimotuzumab promotes radiosensitivity of EGFR-overexpression esophageal squamous cell carcinoma cells by upregulating IGFBP-3. J Transl Med 10: 249, 2012.

25. Baraban E, Sadigh S, Rosenbaum J, Van Arnam J, Bogusz AM, Mehr C and Bagg A: Cyclin D1 expression and novel mutational findings in Rosai-Dorfman disease. Br J Haematol 186: 837-844, 2019.

26. Okamoto I: Epidermal growth factor receptor in relation to tumor development: EGFR-targeted anticancer therapy. FEBS J 277: 309-315, 2010.

27. Li S, Kussie P and Ferguson KM: Structural basis for EGF receptor inhibition by the therapeutic antibody IMC-11F8. Structure 16: 216-227, 2008.

28. Chakravarti A, Winter K, Wu CL, Kaufman D, Hammond E, Parliament M, Tester W, Hagan M, Grignon D, Heney N, et al: Expression of the epidermal growth factor receptor and Her-2 are predictors of favorable outcome and reduced complete response rates, respectively, in patients with muscle-invading bladder cancers treated by concurrent radiation and cisplatin-based chemotherapy: A report from the Radiation Therapy Oncology Group. Int J Radiat Oncol Biol Phys 62: 309-317, 2005.

29. Crosby T, Hurt CN, Falk S, Gollins S, Mukherjee S, Staffurth J, Ray R, BashirN,Bridgewater JA, Geh JI, et al: Chemoradiotherapy with or without cetuximab in patients with oesophageal cancer (SCOPE1): A multicentre, phase 2/3 randomised trial. Lancet Oncol 14: 627-637, 2013.

30. Suntharalingam M, Winter K, Ilson D, Dicker AP, Kachnic L, Konski A, Chakravarthy AB, Anker CJ, Thakrar H, Horiba N, et al: Effect of the Addition of Cetuximab to Paclitaxel, Cisplatin, and Radiation Therapy for Patients With Esophageal Cancer: The NRG Oncology RTOG 0436 Phase 3 Randomized Clinical Trial. JAMA Oncol 3: 1520-1528, 2017.

31. Lu M, Wang X, Shen L, Jia J, Gong J, Li J, Li J, Li Y, Zhang X, Lu $\mathrm{Z}$, et al: Nimotuzumab plus paclitaxel and cisplatin as the first line treatment for advanced esophageal squamous cell cancer: A single centre prospective phase II trial. Cancer Sci 107: 486-490, 2016.

32. Ramos-Suzarte M,Lorenzo-Luaces P, Lazo NG, Perez ML, Soriano JL, Gonzalez CE, Hernadez IM, Albuerne YÁ, Moreno BP, Alvarez $\mathrm{ES}$, et al: Treatment of malignant, non-resectable, epithelial origin esophageal tumours with the humanized anti-epidermal growth factor antibody nimotuzumab combined with radiation therapy and chemotherapy. Cancer Biol Ther 13: 600-605, 2012.

33. de Castro Junior G, Segalla JG, de Azevedo SJ, Andrade CJ, Grabarz D, de Araújo Lima França B, Del Giglio A, Lazaretti NS, Álvares MN, Pedrini JL, et al: A randomised phase II study of chemoradiotherapy with or without nimotuzumab in locally advanced oesophageal cancer: NICE trial. Eur J Cancer 88: 21-30, 2018. 
34. Cheng JC, Klausen C and Leung PC: Hypoxia-inducible factor 1 alpha mediates epidermal growth factor-induced down-regulation of E-cadherin expression and cell invasion in human ovarian cancer cells. Cancer Lett 329: 197-206, 2013.

35. Lin P, Wang W, Cai WJ, Han CR, Sun Y, Li M and Sun BC: Relationship between the expression of hypoxia-inducible factor-1alpha and epidermal growth factor receptor and micro vessel density and their clinical significance. Zhonghua Er Bi Yan Hou Tou Jing Wai Ke Za Zhi 44: 480-485, 2009 (In Chinese).

36. Wouters A, Boeckx C, Vermorken JB, Van den Weyngaert D, Peeters $\mathrm{M}$ and Lardon F: The intriguing interplay between therapies targeting the epidermal growth factor receptor, the hypoxic microenvironment and hypoxia-inducible factors. Curr Pharm Des 19: 907-917, 2013.
37. Peng XH, Karna P, Cao Z, Jiang BH, Zhou M and Yang L: Cross-talk between epidermal growth factor receptor and hypoxia-inducible factor-1alpha signal pathways increases resistance to apoptosis by up-regulating survivin gene expression. J Biol Chem 281: 25903-25914, 2006.

38. Wu P, Liu J, Sun X, Li X, Xing L and Yu J: Enhanced radiosensitizing by sodium glycididazole in a recurrent esophageal carcinoma tumor model. Oncotarget 8: 63871-63880, 2017. 